\title{
Cine DENSE MRI detects delayed mechanical activation of the left ventricular free wall in a canine model of heart failure with left bundle branch block
}

Sophia Cui ${ }^{*}$, Kenneth C Bilchick ${ }^{2}$, Frederick H Epstein ${ }^{1,3}$

From 17th Annual SCMR Scientific Sessions

New Orleans, LA, USA. 16-19 January 2014

\section{Background}

Cardiac resynchronization therapy (CRT) benefits selected heart failure patients; however, CRT has a nonresponse rate of approximately 30-40\%. Important factors that contribute to lead placement decisions and overall CRT success include determination of mechanical dyssynchrony, presence and location of scar, and the identification of late-activated segments. Recent imaging studies have reported progress in the first two areas. Previously, myocardial tagging showed promise for mapping mechanical activation time [1], but analysis of tagged images is time consuming. We investigated the use of cine DENSE to detect regions of late mechanical activation.

\section{Methods}

Cine DENSE at a temporal resolution of $17 \mathrm{~ms}$, in-plane pixel size of $1.4 \mathrm{~mm} \times 1.4 \mathrm{~mm}$ to $2.2 \mathrm{~mm} \times 2.2 \mathrm{~mm}$, and slice thickness of $8 \mathrm{~mm}$ was performed in standard short-axis planes in 4 canines with pacing-induced heart failure and left bundle branch block (LBBB) induced by catheter ablation. Using semi-automatic analysis methods [2,3], regional circumferential strain (Ecc) was determined from the mid-cavity short-axis DENSE images. The time to the onset of contraction (mechanical activation time) was defined as the time at which the slope of each Ecc curve first became negative, as shown in Figure 1. The mechanical activation time was computed for regions that were $5 \times 5$ pixels in size.

${ }^{1}$ Biomedical Engineering, University of Virginia, Charlottesville, Virginia, USA Full list of author information is available at the end of the article

\section{Results}

Cine DENSE showed that the septum underwent early activation, while the late-activated regions were consistently located in the anterolateral and inferolateral segments. These patterns were visualized using time-to-

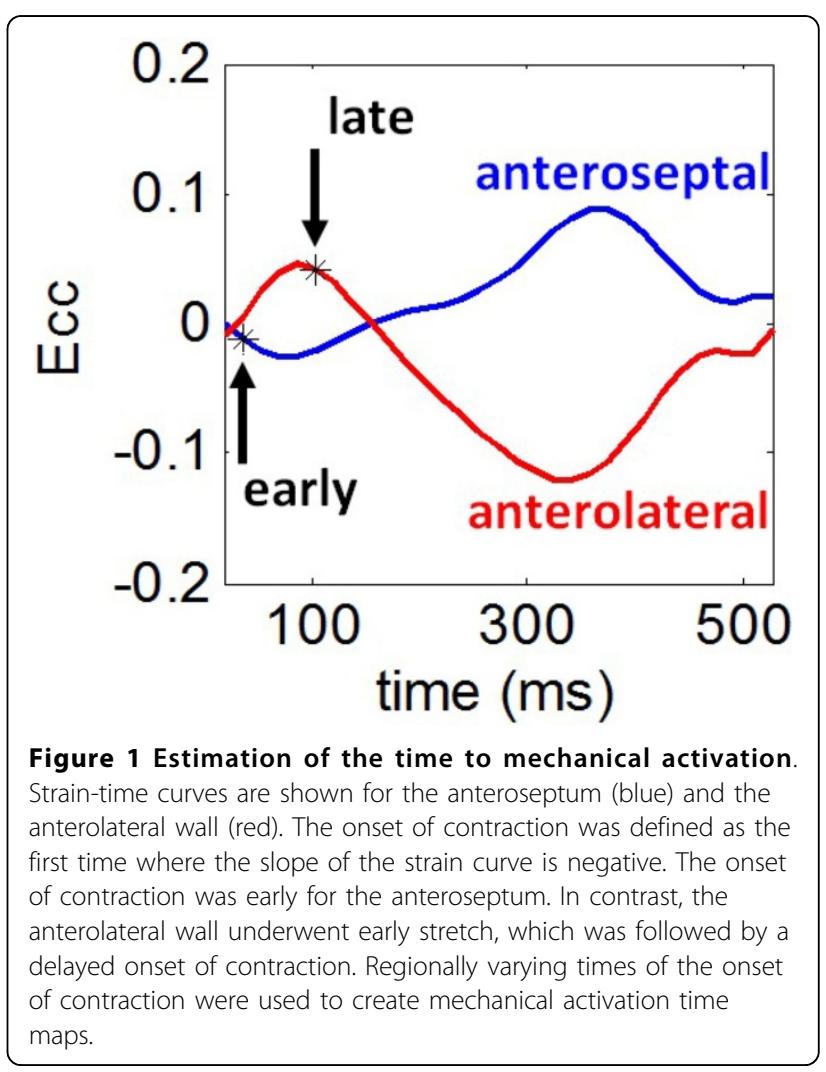


(a) 1 animal
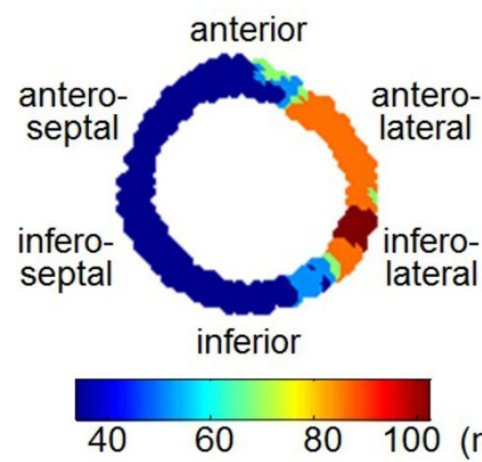

(b) average over 4 animals

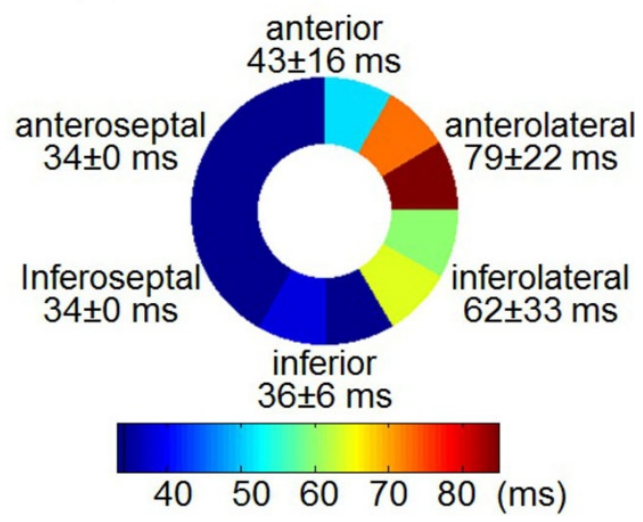

Figure 2 (a) Pixel-wise mechanical activation time map of one canine with heart failure and LBBB. (b) Segmental mechanical activation map of the average time to activation over all four animals. Color indicates the time at which the region was activated.

mechanical-activation maps, as shown in Figure 2a for one animal, and as shown in Figure 2b, which depicts the mean segmental values averaged for all 4 dogs. Early-activated segments underwent contraction within $34 \mathrm{~ms}$ of the imaging trigger, while the mean time for the latest activating segment was $79 \pm 22 \mathrm{~ms}$. Datasets from all 4 dogs depicted a temporal wavefront of activation beginning in the septum and spreading toward the left ventricular free wall. This mechanical pattern agrees with the electrical activation pattern previously reported in LBBB [4].

\section{Conclusions}

Cine DENSE provides sufficient spatial and temporal resolution of LV strain to quantify the propagation of mechanical activation over the LV in a canine model of heart failure and LBBB. The time required to analyze cine DENSE data is much less than for conventional tagging, and completely automated methods have recently been described [5]. Cine DENSE shows promise for quantifying the extent of mechanical dyssynchrony [6], and identifying late-activated regions that would be good candidate sites for LV lead implantation.

\section{Funding}

NIH K23 grant HL094761 and American Heart Association Grant-in-Aid 12GRNT12050301.

\footnotetext{
Authors' details

${ }^{1}$ Biomedical Engineering, University of Virginia, Charlottesville, Virginia, USA. ${ }^{2}$ Cardiovascular Medicine, University of Virginia, Charlottesville, Virginia, USA

${ }^{3}$ Radiology, University of Virginia, Charlottesville, Virginia, USA.
}

Published: 16 January 2014

\section{References}

1. Wyman B, et al: AJP 1999.
2. Spottiswoode B, et al: IEEE 2007.

Spottiswoode B, et al: MIA 2009.

Strik M, et al: JATR 2012

. Gilliam A, Epstein F: IEEE 2012.

6. Bilchick K, et al: JACC 2012.

doi:10.1186/1532-429X-16-S1-069

Cite this article as: Cui et al.: Cine DENSE MRI detects delayed

mechanical activation of the left ventricular free wall in a canine model

of heart failure with left bundle branch block. Journal of Cardiovascular

Magnetic Resonance 2014 16(Suppl 1):069.
Submit your next manuscript to BioMed Central and take full advantage of:

- Convenient online submission

- Thorough peer review

- No space constraints or color figure charges

- Immediate publication on acceptance

- Inclusion in PubMed, CAS, Scopus and Google Scholar

- Research which is freely available for redistribution

Submit your manuscript at www.biomedcentral.com/submit
Biomed Central 